TITLE:

\title{
Ethical and Social Concerns: Opinions of Japanese Life-Science Researchers on Developments in the Science of Mind and Behavior
}

\section{$\operatorname{AUTHOR}(S)$ :}

Higashijima, Jin; Takahashi, Kitetsu; Kato, Kazuto

\section{CITATION:}

Higashijima, Jin ...[et al]. Ethical and Social Concerns: Opinions of Japanese Life-Science Researchers on Developments in the Science of Mind and Behavior. East Asian Science, Technology and Society: An International Journal 2011, 5(3): 359-374

\section{ISSUE DATE:}

2011-09-28

URL:

http://hdl.handle.net/2433/154816

\section{RIGHT:}

(C) National Science Council, Taiwan 2011; This is not the published version. Please cite only the published version.; この論文は出版社版で ありません。引用の際には出版社版をご確認ご利用ください。 
Ethical and Social Concerns: Opinions of Japanese Life-Science Researchers on Developments in the Science of Mind and Behavior

\begin{abstract}
Because of its importance to society, the science of mind and behavior is an academic field in which ethical and social considerations are vital. When examining these issues, the opinions of life-science researchers must be considered. In this article, the authors elicit and describe the opinions of sixty-one Japanese life-science researchers on the ethical and social issues surrounding the science of mind and behavior. The results reveal significant diversity of opinions, especially when the subject was the genetic "enhancement" and "medical treatment" of human mental abilities. Moreover, there was a lack of consensus regarding the application of mind and behavior research to social policy. The results suggest that a wide range of life-science researchers should be involved in discussions of these controversial but socially important issues.
\end{abstract}

\title{
1. Introduction
}

The science of mind and behavior has grown enormously in recent years (Plomin and Oliver 2009). Combining insights from neuroscience, psychological science and life science, this interdiciplinary field hopes to elucidate the genetic aspects of human behavior, mind, and personality (Butcher et al. 2008; British Medical Association 2007; Loat et al. 2008; Galaburda et al. 2006; O’Mathúna 2006; Tang et al. 1990). Many of the research topics addressed by the science of mind and behavior, including autism spectrum disorders and other neurodevelopmental disorders, are expected to contribute greatly to human welfare (Interagency Autism Coordinating Committee 2010).

Mind and behavior research does, however, occasionally elicit serious concerns about its ethical and social implications (Duster 2006; Foster and Sharp 2007; National Center for Human Genome Research 1996; Nuffield Council on Bioethics 2002). There is compelling evidence that behavioral genetics, a core research area, has a strong influence on society. Because its focus is on the differences among certain groups, social reactions should be carefully taken into account. At times, while researching this topic, one flushes out the specter of eugenics. In conjunction with social policies, eugenics programs have reshaped society through such things as the involuntary sterilization of those with mental disabilities (Kevles 1985). 
Today, the life sciences are increasingly able to intervene both directly and indirectly into the human mind and behavior. This field is becoming more influential, with increasing potential to elucidate the genetic influences on human behavior. Thus, it is important to consider the ethical and social impacts of the life sciences of mind and behavior, both in the present and looking into the future (Nuffield Council on Bioethics 2002; Rothstein 2005).

Much of the recent research in this area has addressed issues such as criminal behavior, sexual tendencies, alcoholism, aggressiveness, psychological disorders, and cognitive disabilities. Important but controversial technologies_-including genetic testing, selective abortion, and the enhancement of cognitive and intellectual abilities - can be applied in conjunction with the fruits of such research (British Medical Association 2007; Fisher and Francks 2006; Kovas and Plomin 2006; Posthuma and de Geus 2006; Xu et al. 2008). Such fruits are closely linked to cultural representations and social images, which can have a negative effect on a specific population. And the legal responsibilities of people born with cognitive disabilities can be ambiguous and controversial (Nuffield Council on Bioethics 2002). This combination of factors has led a number of researchers to argue that society is coming to regard issues relating to mind and behavior research as important (Adams 2004; Baoutina et al. 2008; Fenton 2008; Marcum 2008).

Ensuring that scientific knowledge and technology contribute to human welfare is a difficult but important problem; one must consider both the scientific and the cultural factors (Epstein 2007). In many cases there are no simple and precise answers to the question of interest. For example, consider the possibility of intervening in memory function, anecdotally said to improve human wellbeing considerably. On one hand, research in that area can assist patient recovery. However, simply enhancing the ability to retain all information would clearly have negative impacts on selectivity, an important part of the human memory system. In addition to scientific issues of this nature, we must also consider the social impacts of mind and behavior research. Should memory improvement be performed on a "normal" person? Would it truly be beneficial (British Medical Association 2007)? Even if we ignore the benefits and detriments for an individual human life or an entire society, determining the full consequences of memory enhancement is extremely complex and depends on the time, place, and individual involved (Cunningham-Burley 2006).

From all this one may conclude that the time is ripe to examine the social and legal implications of progress in mind and behavioral science; a survey of researchers is essential. Though the field is large and varied (Schaffner 2006a, b), few have participated in discussions aimed specifically at eliciting ethical and social concerns (Adams 2004). The situation is 
especially dire in Japan, one of the leaders in the life sciences.

For the present study, we interviewed sixty-one front-line Japanese life-science researchers. Our aim was to examine and clarify opinions concerning important ethical and societal issues raised by the sciences of mind and behavior. We focused primarily on intervention into the genetic basis for human behavior, a much debated topic. Our findings may serve as a basis for ongoing discussions between life-science researchers and members of Japan's wider society.

\section{Methods}

Interviewer: All interviews were carried out by a Japanese graduate student with a background in both the life sciences and the social sciences.

Subjects: Sixty-one life-science researchers (fifty-six male, five female) were interviewed. This study focused on not only the opinions of "opinion leaders" (i.e., prominent researchers who are active participants in debates on the ethical and social aspects of the study of mind and behavior) but other representative researchers. All of the participants worked in fields that depended on mice for their findings (they studied mouse genes, mouse models, mouse cells, and behavioral phenotypes; see below). We selected researchers working with these mice for several reasons: they are the primary experimental mammal in the life sciences, the experimental technology developed to study them is quite sophisticated, and they bear a certain genetic resemblance to humans. This guaranteed a large pool of front-line researchers to choose from. Furthermore, there is a substantial amount of mouse-related life-science research that potentially relates to the genetic "enhancement" of humans (Tang et al. 1999).

We used a method similar to purposive sampling to select our interviewees as follows. First, we divided academic disciplines into small categories according to such traits as research topics and methods. Then we made up lists of potential candidates from each research topic, using the proceedings of conferences and meetings related to various disciplines. Candidates were then selected from the lists based on the number of research papers they had published, their area of research, gender, academic position, and location. All of those selected had published more than three peer-reviewed academic papers and held academic positions (predominantly associate and full professors). Most lived in the Kansai and Kanto areas of Japan, where Tokyo, Osaka, Yokohama, Kobe, and Kyoto are found-lively areas both economically and scientifically. By means of email, we invited ninety-one researchers to participate in our study; sixty-eight responded favorably, and from this group we selected 
sixty-two people for formal participation. In addition, without considering their academic position we also included two researchers who were recommended by participants. Ultimately, we excluded three of the respondents because they had failed to answer core questions (see below).

Interview: Interviews were carried out between July 2005 and December 2007. We used a semi-structured format. Each interview lasted an average of ninety minutes and consisted of a set of core questions, which were asked in varying orders. To capture the subjects' opinion, the language used during interviews was tailored to their vocabulary and area of expertise. All interviews were conducted in Japanese. The first language of all participants was Japanese, except one individual who reads and writes Japanese proficiently. Core questions focused on the relationship between life sciences of mind and behavior and society, and the development of genetic technologies affecting human mental activities. These questions were combined with others that aimed to elicit the respondents' opinions on research employing mouse models and the transmission of information from life scientists to society (Higashijima et al. 2008; Higashijima et al. 2009a; Higashijima et al. 2009b). Due to time constraints, some respondents were not able to answer all of the questions.

The procedure was also modified during the interviewing period: we decided to cease making tape recordings out of concern that the presence of the recorder might distort opinions.

Analysis: While analyzing our data, we tried to clarify the differences in opinions expressed by various respondents in detail, though it was difficult to compare and examine every opinion. Therefore, we have classified the opinions, using a percentage of the respondents as a rough guide to general trends: small differences were not considered quite meaningful in our analysis.

For analysis, each data set was first categorized according to its contents. For some questions, respondents were shown a number of options to choose from (ex. positive/negative/others) and then asked to explain their choice. Data were then classified again by two graduate students who assigned 0.5 points to every answer that corresponded with a relevant item on the category list. During this process, the list was refined several times to reflect important aspects of the data. The sum of the points assigned to each item on the list was divided by the number of respondents (giving a modified percentage of respondents). Thus, if approximately 85 percent of respondents who had talked about something concerning item A had answered "A," that item was assigned a figure of 85 .

In order to measure inter-coder reliability, we calculated the percentage of agreement 
(Francisco et al. 2006). If the agreement percentage was 95 percent, the classifiers' agreement with respect to answer scoring was 95 percent as well.

Some respondents commented on existing Japanese laws and guidelines regarding research environments. Because these answers were irrelevant to our questions, they were put into the "other" category.

Because of the scoring system, the total modified percentages did not always total 100 , containing rounding errors and responses corresponding to "other" category.

Statistical analysis: We used SPSS 14.0 software and chi-square tests for statistical analysis. Because our primary purpose was to elicit and describe life scientists' opinions, only minimal statistical analysis was necessary.

\section{Results}

\section{Respondent characteristics}

Academic degrees: Of the sixty-one participants, twenty-four held doctorates in medical science (twenty-two of the twenty-four PhD's were also medical MD's). Another twenty-one held doctorates in other branches of science. Eight participants held doctorates in pharmaceutical sciences, four in agriculture, two in psychology, and two in dental science.

Academic societies: Among the respondents, 73 percent belonged to the Molecular Biology Society of Japan (日本分子生物学会), 39 percent to the Japanese Biochemical Society (日本 生化学会), 30 percent to the Japanese Neuroscience Society (日本神経科学学会), 25 percent to the Japanese Cancer Association (日本癌学会), 22 percent to the Japanese Society of Developmental Biologists (日本発生生物学会), 19 percent to the Japanese Society for Immunology (日本免疫学会), 14 percent to the Japanese Society for Cell Biology (日本細胞 生物学会), and 13 percent to the Pharmaceutical Society of Japan (日本薬学会).

\section{A. The relationship between society and research on mind and behavior}

(a) Benefits: Researchers' responses regarding the positive effects of mind and behavior research are summarized in Figure 1. In response to a series of different formulations of the question, most respondents ( 85 percent) indicated that they considered life-science research on the mind and behavior to be useful when helping ordinary people to understand themselves. However, there were some respondents who had differing opinions (15\%), including some who 
did not consider this kind of research as useful for human society (5\%). A few examples of replies follow:

(Yes.) Helpful. For example, if we regard "war" as a disease affecting the human mind, it's possible that we can "cure" the disease. However, I do not think that our genes account for everything.

(Yes.) Difficult question. The knowledge can help each person to deepen their understanding of themselves. But I know that my point-of-view is not a common one in our society.

(No.) I don't think this kind of research is helpful for ordinary people. Scientific knowledge is in a different dimension to the daily lives of the general public. Well, in the long run, I believe that it is better for our society to have this sort of scientific knowledge - it presents the traits of our own species. There is no need to conceal this knowledge from our society. I think that this kind of scientific knowledge is far better than pseudoscience.

(Other.) I think that framing the question in terms of "useful or not" is completely wrongheaded.

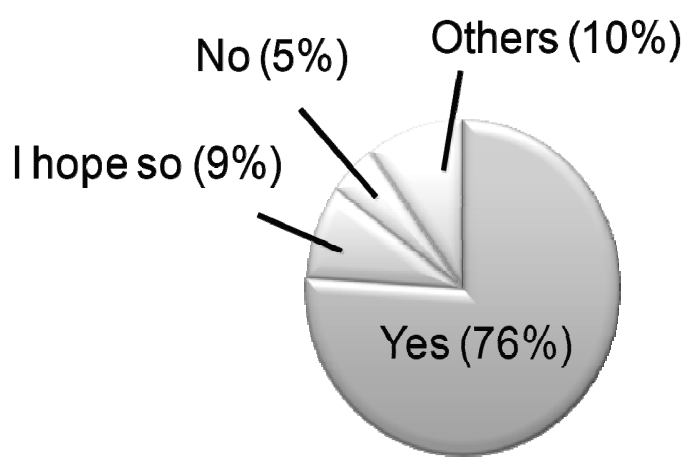

Figure 1. Answers to the question "Does life sciences of human behavior and/or mind help ordinary people understand themselves?"

(Percent agreement $=96 \%$, Number of respondents $=46)$ 


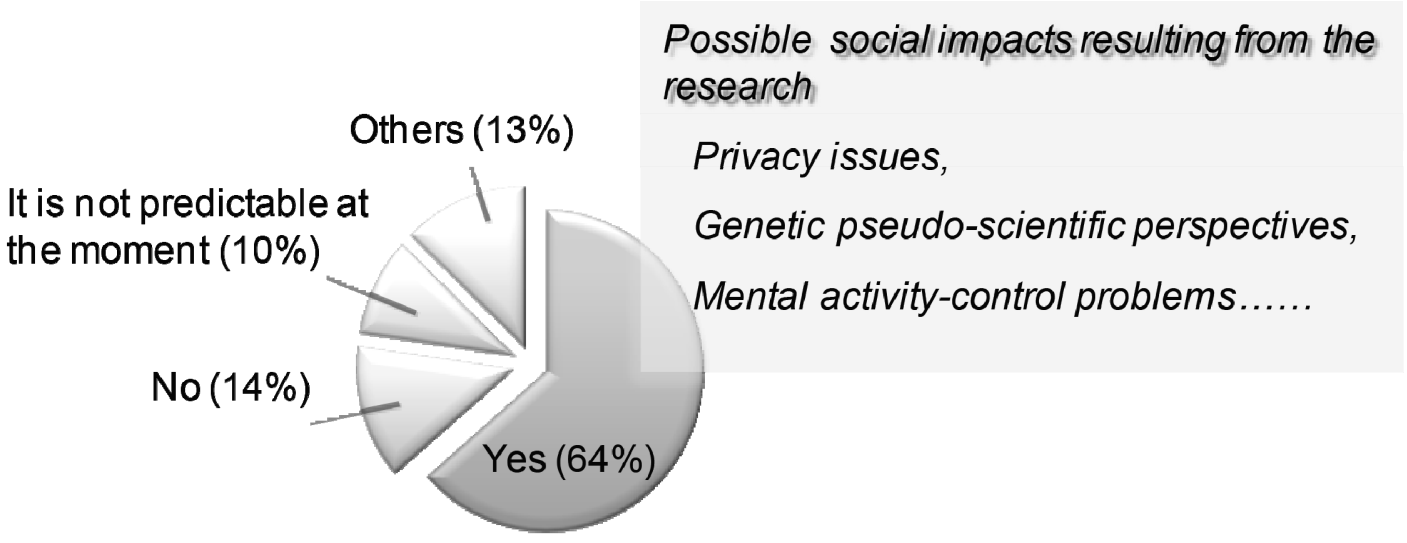

Figure 2. Answers to the question "Is it possible that issues will emerge from progress in life sciences of behavior, mind, or cognitive function?"*

(Percent agreement $=88 \%$, Number of respondents $=43$ )

* Notethat total percentage of respondents is not always $100 \%$

(See Analysis in methods).

(b) Social and ethical issues emerging from the study of the mind and behavior by the life sciences: When asked about the possible implications of research into the mind, more than half of the respondents ( 64 percent) stated that problems associated with such studies were becoming increasingly relevant to our society (Figure 2). Note that respondents often gave ambiguous answers: they had never thought seriously about these issues.

Privacy and confidentiality were the most commonly mentioned issues (13 percent each):

If information about an abnormality in a given gene mutation were to be used in a clinical diagnosis, precautions should be taken to avoid leaking any personal information. When it comes to the human mind, not only are hereditary factors highly influential, but so are environmental factors. In other words, genetic factors should not be regarded as absolute.

Problems with mental function were also referred to (12 percent), and some respondents raised the issue of mind-altering drugs ( 7 percent). 
Issues will crop up in the legal domain, philosophical ones such as to what degree a criminal can be blamed if he/she has a specific combination of genetic variations engendering an antisocial personality out of the range of any psychiatric disease.

Some respondents were concerned about pseudoscientific notions about genetics ( 5 percent) or genetic determinism (4 percent). Some also cited the effects of the commercialization of genetic testing ( 5 percent), noting the legal implications of genetic research.

Asked about the broad social influence of life-science research on the mind and behavior, 23 percent of respondents anticipated significant changes in social systems. They predicted that the extent of these changes would largely depend on three factors: the degree of the research developments ( 7 percent), professionals who apply emerging technology to mental and behavioral issues in both the private and the public sectors ( 5 percent), and gene function brought about by the mind and behavior research ( 4 percent). NB: The questions mentioned "possible" rather than inevitable problems and implications.

Some respondents did not believe that specific problems would arise from behavior and mind research (15 percent); more than 10 percent considered the upshot of research to be unpredictable.

Thinking rationally about it, there aren't any problems. It's reasonable to suggest that no scientific finding has necessary social implications. If anything, I think it's society's fault. [.. .] We cannot run away from scientific facts. I believe that unless we face scientific facts rationally and make them a foundation for our thoughts, our world may become a sham, a fake.

(c) Application of mind and behavior research to social policy: The relationship between mind and behavior research and society can be construed as a social policy issue. In our interviews, we asked for their opinions about applying their research to social policies. The responses were significantly divided, and they raised a wide range of issues. On one hand, more than 40 percent of respondents believed that the results of their research should not be applied to social policy (Figure 3) . 


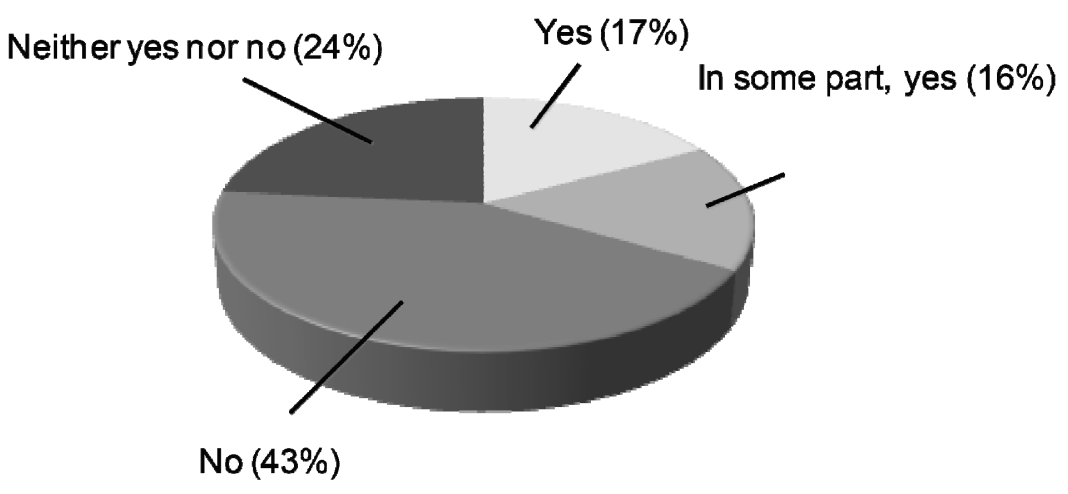

Figure 3. Answers to the question "Do you support the application of life sciences of mind and behavior to social policy?"

$$
\text { (Percent agreement }=93 \%, \text { Number of respondents }=46)
$$

Table 1. Answers to the question "Are there any communication gaps between life sciences researchers and humanities researchers such as philosophers/ethicists due to their excessive emphasis on the negative aspects of the life sciences?"

(Percent agreement $=91 \%$, Number of respondents $=29$ )

\section{Answers}

Yes

I have such experience

I know some life sciences researchers who had such experience

I agree with you although I have no concrete example or experience

No

I have never experienced such gaps

I do not have such impression

I do not know

I have never communicated with such peoples
$\%$

47

All answers are mutually exclusive. 
I've never thought about it. I am basically against such applications at present. I think our society is not ready to accept such applications. Also, social security is not enough. It should be mentioned, though, that it will be impossible to stop this kind of social application in the future.

[That would be a] terrible mistake! When we compare the innate and learned aspects of human personality, we find learned aspects far more important. Thus, we can modify human personality more effectively by changing the environment. So why should we regulate genetic behavioral traits through social policies, applying research from the study of mind and behavior? It's far more risky than beneficial. It relies on an oversimplified view that everything can be explained by biology.

I think it would be difficult. Personally, I do not want it applied to social policy, although I know the importance of what is called "prediction" of a specific, for example criminal, human tendency.

Research related to the life sciences of mind and behavior does not easily fit into social policy. It is suited to the medical treatment of clinical conditions, not arbitrary decision-making. [...] It is a matter of what is normal and what is abnormal. I mean, when a condition exceeds its normal range, it is called a disease. It is not the business of biology to intervene when a case is within the normal range.

However, about 30 percent of respondents did support applications to social policy-at least to some extent. Some claimed that life sciences of mind and behavior had already influenced social policy (5 percent), and 14 percent considered such an influence unavoidable.

I agree with the ideas of such applications. Still, it is nonsense to place science above everything else. In the process of seeking out positive applications, it is important to take everyone's opinions into account.

Knowledge drawn from the life sciences of mind and behavior is effective when solving educational problems such as Japan's “Nursing the Brain Project." Our lives cannot be evaluated separately; we evaluate them as a whole, and we cannot 
know what kind of life is happy until its end. For example, a good memory can be a great asset in economic matters. But in terms of other activities in our daily lives, I do not think an extremely good memory has any other advantages. It's a difficult issue.

It depends on the extent. [. . . I I think this kind of occupational difference involving genetic traits already exists. Various things become clear as time passes. We should also consider the range of personal information, although I know there are kinds of information that should be kept secret.

Yes, but with limits. [ . . .] Unlike the "average" story, I think it is difficult to deal with individual cases. In other words, I agree with the application of mind and behavior research to social policy when it becomes possible to take care of each individual trait.

When talking about such applications, we should consider two dimensions. Few of the results from research into genetic variation as it relate to higher brain functions are applicable to public policy. We should also consider the problems related to personal information. In terms of social equality, our society should accept variations in human traits as long as it they fall within a socially acceptable range. [...] We should also consider how research results may get oversimplified as they spread widely. In such oversimplified versions, interactions between genetic factors and other environmental factors are neglected, which can contribute to prejudice. [.. .] I think that mind and behavior research results are useful only for a very limited number of case outside of clinical psychiatry. It may be helpful when conducting psychiatric evaluations.

Respondents who offered predictions of emerging social implications generally tended to exhibit a positive attitude toward the representation of mind and behavior research in social policies $(\mathrm{p}=0.022)$.

Some respondents referred to communication problems, particularly between the life sciences and the humanities (Table 1). Almost 50 percent mentioned communication gaps. (Unfortunately many respondents were not able to respond to this question. Among those who did respond, only 6 percent said they had communicated with humanities researchers, 
explaining that there had been no need for such discussions.)

Yes, there are communication problems. For example, at present in Japan, and from the viewpoint of Kantism or eugenics, humanities researchers who are also members of the Science Council of Japan are persistently against ES (embryonic stem) cell research. Technical developments will change social attitudes, as was the case with blood transfusions.

There are some communication gaps. Philosophers should learn more about biology. Why don't they take a realistic look at our lives?

I have never discussed ethical or social aspects of the life sciences of mind and behavior with humanities researchers. When such conversations do take place, we scientists should convey the significance of environmental factors. I know it's difficult. I'm wondering about the extent to which philosophy reflects the opinions of the general public. If philosophers set forth their opinions as if they spoke for the general public, without ever checking anything, it makes the relationship between life-science researchers and philosophers difficult.

In Europe and North America, there seems to be some kind of gap between life-science researchers and humanities scholars. But in Japan, there are few such cases. The life sciences may be similar to philosophy, epistemologically speaking. Simplification is the way of science, whereas it is philosophers who grasp a the world whole and unsimplified.

I've never noticed this. I know some philosophers who have a good understanding of the life sciences.

\section{B. Genetic technologies that could affect human mental abilities}

(a) Basic attitudes: Figure 4 shows respondents' opinions toward technological developments that have the potential to affect the genetic basis of human mental abilities. Their opinions varied dramatically. Almost 50 percent took a neutral stance, 20 percent were in favor, and 30 percent were opposed. Note that each attitude (favorable, opposed and neutral) was chosen by the respondents themselves. 


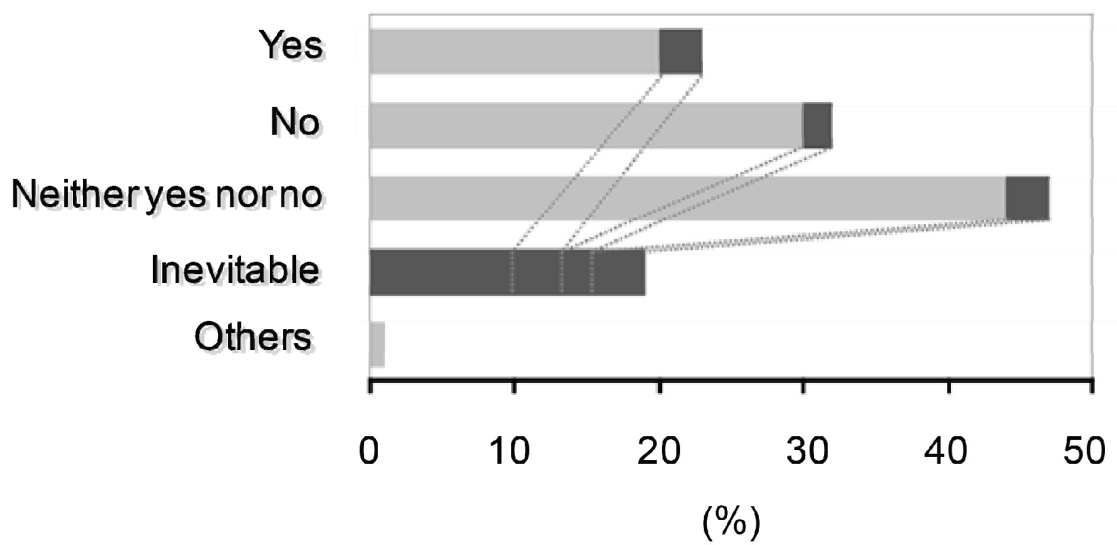

Figure 4. Answers to the question "Do you support the technological developments that allow us to intervene in human behavior, mind, or cognitive function genetically ?" (Percent agreement $=91 \%$, Number of respondents $=54)$

(Favorable.) We cannot say no, because we cannot stop the progress of science.

I'm positive about it. Mental activities are based on substance. That is a fact, though I cannot believe that such material bases are the only basis of our mental phenomena.

(Favorable.) I agree, though I do not want to have that kind of operation.

(Favorable.) It is better for humans to have such technology. Deciding whether to apply such technologies to an individual must be decided case by case.

(Neutral.) I'm not negative about that kind of technology. [I'd] permit them if they can be developed, but there will be disagreements as to the ideal human form. Technological development is not necessarily bad, though it is difficult to decide which human traits are good and which are bad.

(Neutral.) Neither yes nor no. Anyway, the technologies will emerge whether or not we allow it. I think it is important to make them useful to human beings. 
(Neutral.) Difficult question. There are some diseases for which such an operation is necessary. The problem is that existing model organisms - mice, for example - are inadequate for modeling every human situation. In developing such technologies, we must apply them directly to humans as well. [...] We must ask whether that kind of operation corresponds to a medical treatment. Is it acceptable to society?

(Opposed.) Scientists should not permit technologies to be developed with the aim of applying them to humans. For basic research using mice, there is no problem. But human applications are too dangerous. It is important to separate applications from the basic aspects of research problems. There is the possibility that someone could abuse this sort of technology if it were applied. I think that even if that kind of technology can be applied as a medical treatment, it should definitely be prohibited.

(Opposed.) [Any] intervention at the level of the germ line, even at a developmental level, I am definitely against.

(Opposed.) Even in low-level gene therapy, there remains a lot that is largely unknown. [...] The identification of a given gene and the control of a given gene are completely different things. [. . .] Take, for example, organ transplants: you never know the social merits or demerits until you try. The outcome depends on the maturity of the society.

With respect to such genetic technologies, 29 percent of respondents deemed it necessary to regulate them, while almost 25 percent emphasized the importance of accumulating sufficient scientific knowledge to assess risks and benefits (Table 2). This included 13 percent of respondents, who mentioned that it would be important to have academic discussions comparing the risks and benefits of a given technology. Approximately 20 percent of respondents emphasized the value of society-wide discussions and consensus, and 15 percent recommended case-by-case decision-making. Respondents receptive to genetic interventions tended to mention that acquiring additional scientific knowledge was a necessary precondition $(\mathrm{p}=0.022)$.

(b) Acceptable and unacceptable genetic interventions into human mental abilities: Opinions were as follows (see also Table 3): 40 percent of the respondents accepted the validity of 
Table 2. Necessary things to be considered with the development of genetic technologies that intervene in human mental abilities.

$($ Percent agreement $=91 \%$, Number of respondents $=54)$

Comments

Regulations concerning technical developments in related technologies

Accumulation of sufficient scientific knowledge

Social discussions and consensus concerning a given technology

Case-by-case decisions and responses

Announcement of the technological risks to the public

\section{(\%)}

Multiple answers allowed.

intervening to improve mental acuity; 25 percent approved of intervening to raise the mental abilities of mentally challenged individuals from below average to average. Of these respondents, few explained their views clearly. In other words, the meanings of "average" and "normal" mental capacity were often not defined. Approximately 10 percent of respondents considered all genetic interventions into human mental activity to be inappropriate. Of the 25 percent who considered interventions to achieve cognitive enhancements impermissible, almost all admitted that there were no clear-cut distinction between medical treatment and enhancement. Some respondents simply regarded the question as unanswerable. Significant concerns were raised about the effectiveness ( 26 percent), reversibility ( 16 percent), and safety ( 12 percent) of the interventions.

(Acceptable: Corresponding to medical treatments whose effectiveness is guaranteed.) Basically, disease treatment is all right. [. . .] We can consider that kind of treatment if we are certain it's safe.

(Acceptable: Raising individual from below-average to average.) It is acceptable to raise someone's mental level to an average level. 
(Acceptable: Raising individual from below-average to average. Unacceptable: Enhancement.) The important question is to what degree we may intervene in human mental abilities. I think genetic treatment for patients with Down's syndrome or Asperger's syndrome should be allowed. [But] there is no need to treat normal people.

(Acceptable: Raising individual from below-average to average.) If we are talking about something like working-memory dysfunctions that hinder our daily lives, I think improving faulty functions is allowable.

(Acceptable: Within criteria established by social consensus.) That is a difficult question. The criteria should be determined through social discussions that involve life-science researchers.

(Acceptable: In individual with criminal tendencies.) We should consider people in need. For example, a person who commits crimes again and again will need medical attention in the future. It is necessary to obtain public understanding of such treatments, though people never think about such kinds of issues, and of course they would say "no."

(Unacceptable: All possible interventions unacceptable.) I'm completely opposed to irreversible genetic operations on humans.

Regarding genetic interventions, several respondents raised issues they felt should be considered: 23 percent reported that it was difficult to distinguish between appropriate and inappropriate interventions; 13 percent pointed out the lack of a clear boundary between individual variations and disorders; approximately 20 percent emphasized the need to acquire more scientific knowledge; some expressed concerns about the negative effects of commercializing the relevant technology.

Furthermore, when asked about genetic intervention into human mental activities, 15 percent answered, "I don't know"; 8 percent said that the question was not "realistic and answerable"; and some respondents (6 percent) gave answers that were classified as "other."

One question was: "Who should be empowered to make judgments with respect to such interventions?" Global consensus was necessary, said 14 percent of the respondents. An equal 
number felt that national approval was necessary, while 7 percent spoke of "public" approval. Scientists should take the lead, said 2 percent, while judgments by medical staff ( 6 percent) and patients' relatives (19 percent) were also considered important.

Table 3. Acceptable and prohibited interventions in human mental abilities

(Percent agreement $=94 \%$, Number of respondents $=44$ )

\section{Acceptable interventions}

Corresponding to medical treatments

Raising in dividuals from below-average to average levels*

With in criteria established by social consensus

For which effectiveness is guaranteed

That are not inheritable

With drug or medicines

In patients with life-threatening diseases

That are reversible

In individuals with criminal tendencies

\section{Prohibited interventions}

Enhancements

All possible interventions are forbidden

*These interventions are intended to raise individuals with below-average abilities, including disabled or impaired persons and/or persons who are below average due to acquired or injuries to average level. Multiple answers allowed. 


\section{Discussion}

This study examined the views of Japanese life-science researchers on ethical and social issues prompted by developments in the biological studies of mind and behavior. Our study highlights some controversial issues such as applying mind and behavior research to social policy, and we have noted disagreements regarding interventions to modify human cognitive abilities.

The most significant result was the lack of any clear consensus regarding the implications of the life sciences of mind and behavior for social policy. Some researchers were sanguine about the potential contributions in this area, while others were cautious and less than hopeful. This kind of divide in researchers' attitudes should be considered as individuals, institutions, and states assess the ethical and social implications of research, especially when discussing the application of controversial new technologies.

The divergence may be closely linked to another finding. When discussing the distinction between gene therapy and the genetic enhancement of human mental ability (a good example of one of the controversial issues mentioned above), there was much disagreement. Defining an acceptable range of human mental ability beyond which intervention is acceptable proved extremely difficult, particularly when solutions were drawn from the life sciences alone.

Should such therapy become a possibility, scholars and officials must go to great lengths to explain the subject clearly to general public; ignorance and confusion must be avoided, and broad discussions must be encouraged.

Another point to keep in mind is the need for framing discussions in terms relevant to society at large. For example, the researchers we interviewed tended to use "deviations from the average" or "normality" to determine whether to approve of interventions. However, the value of "average" changes as a population evolves, and there are several different ways to define "normality" (Wachbroit 2006). The enhancement conundrum is not a new problem (Wolpe 2002; Savulescu et al 2006). It is not merely seen as a scientific or philosophical issue - most recognize it as an important issue for human society. Previous authors have suggested that at a purely theoretical level it is difficult to delineate a logical and definitive distinction between enhancement and treatment (Baylis and Robert 2004; British Medical Association 2007; Caplan and Elliott 2004; Dickens 1996; Loftis 2005).

The difficulty involved in eliciting firm solutions from the life sciences alone confirms the importance of broad discussions of such topics, as well as discussions among members of the scientific community. Our results indicate that as those discussions take place it would be insufficient to rely on a few leading researchers to make decisions. A number of researchers from various backgrounds are needed to clarify ambiguities and differences of opinion. 
Moreover, researchers should be encouraged to participate fully in dialogues with members of the public. One example of an effective discussion process that has already taken place has been published as a discussion paper by the British Medical Association: "Boosting your brainpower: Ethical aspects of cognitive enhancements." The goal of that paper was to "inform public debate about how, as a society, we should respond to these developments" (British Medical Association 2007).

Despite some methodological limitations, our study provides a baseline map of the general opinions held by Japanese life-science researchers about the ethical and social issues raised by recent developments in mind and behavioral science. We believe that our conclusions are not specific to Japan, and that our findings may represent a starting point for the international discussions that will be necessary to avoid undesirable social consequences of mind and behavior research.

As mentioned in the introduction, the history of experimental research on the mind and behavior, particularly the eugenics movements, has shown just how grave the consequences of this branch of academia can be for society. At present, technologies that make it possible to intervene in the human mind are already widespread (one thinks of proactive drugs like Ritalin and Prozac), and others may be developed regardless of public awareness or concerns. This research is not risk-free. Although it is difficult to identify and anticipate all of the problems that may crop up, we must be aware of future possibilities and deal with them appropriately. One important step towards this goal is to acknowledge and address the diversity and abundance of current opinions among life-science researchers, especially when it concerns scientifically and socially ambiguous problems emerging from mind and behavior research.

\section{Acknowledgments}

We would like to thank the life scientists who took time from their busy schedules to participate in this study. Also, we are deeply grateful to Troy Duster for his thoughtful and helpful comments on our work. Finally, we appreciate the helpful comments of two anonymous reviewers. This work was supported by a KAKENHI (Grant-in-Aid for Scientific Research) on Priority Areas Applied Genomics from the Ministry of Education, Culture, Sports, Science, and Technology (MEXT) of Japan to Kazuto Kato (17019032).

\section{References}

Adams, H. (2004). A human germ line modification scale. The Journal of Law, Medicine and Ethics 32: 164-173. 
Baoutina, A., I. E. Alexander, J. E. J. Rasko, and R. K. Emslie. (2008). Developing strategies for detection of gene doping. The Journal of Gene Medicine 10: 3-20.

Baylis, B., and S. J. Robert. (2004). The inevitability of genetic enhancement technologies. Bioethics 18 : 1-26.

British Medical Association, Expert Group on Cognitive Enhancements, Editorial Board, Medical Ethics Committee. (2007). Boosting your brainpower: ethical aspects of cognitive enhancements: a discussion paper.

http://www.bma.org.uk/ethics/health_technology/CognitiveEnhancement2007.jsp, accessed November 5, 2009.

Butcher, M. L., P. S. O. Davis, W. I. Craig, and R. Plomin. (2008). Genome-wide quantitative trait locus association scan of general cognitive ability using pooled DNA and 500K single nucleotide polymorphism microarrays. Genes, Brain and Behavior 7: 435-446.

Caplan, A., and C. Elliott. (2004). Is it ethical to use enhancement technologies to make us better than well? PLoS Medicine 1: 172-175.

Cunningham-Burley, S. (2006). Public knowledge and public trust. Community Genetics 9: 204-210.

Dickens, M. B. (1996). Legal and ethical challenges in gene therapy. Transfusion and Apheresis Science 17: 191-196.

Duster, T. (2006). Behavioral genetics and explanations of the link between crime, violence, and race. In Wrestling with behavioral genetics: Science, ethics and public conversation, edited by E. Parens, R. A. Chapman, and N. Press, 141-167. Baltimore: Johns Hopkins University Press.

Epstein, S. (2007). Patient groups and health movements. In The handbook of science and technology studies (3rd ed.), edited by E. J. Hackett, O. Amsterdamska, M. Lynch, and J. Wajcman, 499-539. Cambridge, MA: MIT Press.

Fenton, E. (2008). Genetic enhancement—a threat to human rights? Bioethics 1: 1-7.

Fisher, E. S., and C. Francks. (2006). Genes, cognition and dyslexia: Learning to read the genome. Trends in Cognitive Sciences 6: 250-257.

Foster, M. W., and R. R. Sharp. (2007). Share and share alike: Deciding how to distribute the scientific and social benefit of genomic data. Nature Reviews Genetics 8: 633-639.

Francisco, M. L., R. Francisco, and M. Teodoro. (2006). Assessment of interjudge reliability in the open-ended questions coding process. Quality and Quantity 40: 519-537.

Galaburda, M. A., J. LoTurco, F. Ramus, H. R. Fitch, and G. D. Rosen. (2006). From genes to behavior in developmental dyslexia. Nature Neuroscience 9: 1213-1217. 
Higashijima, J., K. Takahashi, and K. Kato. (2008). Heterogeneity among life sciences researchers: Why should we consider it seriously? Proceedings of Third International Applied Ethics Conference, Sapporo, Japan, November.

Higashijima, J., K. Takahashi, and K. Kato. (2009a). "Mouse model”: What do Japanese life-science researchers mean by this term? Journal of Science Communication 08.01, A01.

http://jcom.sissa.it/archive/08/01/Jcom0801\%282009\%29A01, accessed May 5, 2011. Higashijima, J., K. Takahashi, and K. Kato. (2009b). 日本のマス・メディアと生命科学情 報：生命科学研究者の意見から (Mass Media and Life Science Information in the Japanese Society: the Japanese Life Science Researchers' Point of View). Japanese Journal of Science Communication 5: 53-65.

JJSC website, http://eprints.lib.hokudai.ac.jp/dspace/handle/2115/36208, accessed May 5, 2011.

Interagency Autism Coordinating Committee. (2010). The 2010 Interagency Autism Coordinating Committee Strategic Plan for Autism Spectrum Disorder Research-January 19, 2010. http://iacc.hhs.gov/strategic-plan/2010/, accessed May 5, 2011.

Kevles, J. D. (1985). In the name of eugenics: Genetics and the uses of human heredity. Cambridge, MA: Harvard University Press.

Kovas, Y., and R. Plomin. (2006). Generalist genes: Implications for the cognitive sciences. Trends in Cognitive Sciences 5: 199-203.

Loat, S. C., A. M. C. Haworth, R. Plomin, and W. I. Craig. (2008). A model incorporating potential skewed X-inactivation in MZ girls suggests that X-linked QTLs exist for several social behaviours including autism spectrum disorder. Annals of Human Genetics 72: 742-751.

Loftis, R. J. (2005). Germ-line enhancement of humans and nonhumans. Kennedy Institute of Ethics Journal 15: 57-76.

Marcum, A. J. (2008). Reflections on humanizing biomedicine. Perspectives in Biology and Medicine 3: 392-405.

National Center for Human Genome Research. (1996). Review of the ethical, legal, and social implications of research programs and related activities, 1990-1995. N.p., National Center for Human Genome Research.

Nuffield Council on Bioethics. (2002). Genetics and Human Behavior: The ethical context. http://www.nuffieldbioethics.org/fileLibrary/pdf/nuffieldgeneticsrep.pdf, 
accessed May 5, 2011.

O’Mathúna, P. D. (2006). Human dignity in the Nazi era: Implications for contemporary bioethics. BMC Medical Ethics $7: 2$.

Plomin, R., and S. P. D. Oliver. (2009). The future of genetics in psychology and psychiatry: Microarrays, genome-wide association, and non-coding RNA. Journal of Child Psychology and Psychiatry 1-2: 63-71.

Posthuma, D., and C. J. E. de Geus. (2006). Progress in the molecular-genetic study of intelligence. Current Directions in Psychological Sciences 4: 151-155.

Rothstein, A. M. (2005). Applications of behavioral genetics: Outpacing the science? Nature Reviews Genetics 6: 793-798.

Savulescu, J., M. Hemsley, A. Newson, and A. Foddy. (2006). Behavioural genetics: Why eugenic selection is preferable to enhancement. Journal of Applied Philosophy 23: $157-171$.

Schaffner, F. K. (2006a). Behavior: Its nature and nurture, part 1. In Wrestling with behavioral genetics: Science, ethics, and public conversation, edited by E. Parens, A. R. Chapman, and N. Press, 3-39. Baltimore: Johns Hopkins University Press.

Schaffner, F. K. (2006b). Behavior: Its nature and nurture, part 2. In Wrestling with behavioral genetics: Science, ethics, and public conversation, edited by E. Parens, A. R. Chapman, and N. Press, 3-39. Baltimore: Johns Hopkins University Press.

Tang, Y., E. Shimizu, G. R. Dube, C. Rampon, G. A. Kerchner, M. Zhuo, G. Liu, and J. Z. Tsien. (1999). Genetic enhancement of learning and memory in mice. Nature 2: 63-69.

Wachbroit, R. (2006). Normality and the significance of difference. In Wrestling with behavioral genetics: Science, ethics and public conversation, edited by E. Parens, A. R. Chapman, and N. Press, 235-253. Baltimore: Johns Hopkins University Press.

Wolpe, R. P. (2002). Treatment, enhancement, and the ethics of neurotherapeutics. Brain and Cognition 50: 387-395.

Xu, B., L. J. Roos, S. Levy, J. E. van Rensburg, A. J. Gogos, and M. Karayiorgou. (2008). Strong association of de novo copy number mutations with sporadic schizophrenia. Nature Genetics 7: 880-885. 